\title{
Evolução da esclerite nodular com biomicroscopia ultrassônica: relato de caso
}

\section{Evolution of nodular scleritis with ultrasound biomicroscopy: case report}

Andrea Alejandra Gonzalez Martinez ${ }^{1}$, Kimble Teixeira Fonseca Matos ${ }^{1}$, Virgínia Trevisani ${ }^{1,2}$, Alcides Hiral ${ }^{1}$, Norma Allemann ${ }^{1}$

\section{RESUMO}

Estabelecer padrão evolutivo de um caso de esclerite nodular à ultrassonografia de alta frequência durante $o$ tratamento. Mulher, 27 anos, com manifestação inicial de uveíte intermediária, edema macular bilateral após tratamento clínico com corticosteroide tópico e via oral. Após quatro meses, observou-se a formação de um nódulo escleral no olho direito quando foi submetido à ultrassonografia de alta frequência (Paradigm, transdutor de $50 \mathrm{MHz}$, técnica de imersão). A lesão do olho direito foi caracterizada à ultrassonografia de alta frequência como uma lesão nodular da parede anterior temporal inferior associada à redução localizada da espessura da escleral. Após a injeção intravítrea de triancinolona para tratamento do edema macular, observou-se a regressão clínica do nódulo escleral no olho direito, mantendo reduzida a espessura escleral. A ultrassonografia de alta frequência auxiliou no diagnóstico da esclerite nodular durante as fases de tratamento e na identificação da sua sequela característica, o afinamento escleral.

Descritores: Esclerite/diagnóstico; Esclerite/ultrassonografia; Ultrassonografia/ métodos; Microscopia/métodos; Relato de caso

\begin{abstract}
To stablish evolutionary pattern of a case of nodular scleritis with high frequency ultrasound during treatment. Twenty-seven year old female, initial manifestation of intermediate uveitis, bilateral macular edema after clinical treatment with topical and oral steroids. After four months, we observed the formation of a scleral nodule in the right eye when patient underwent high frequency ultrasound (Paradigm, 50 $\mathrm{MHz}$ transducer, immersion technique). The lesion in right eye was characterized at high frequency ultrasound as a nodular lesion located at the anterior inferior temporal wall associated with localized reduction of scleral thickness. After intravitreal injection of triamcinolone for treatment of macular edema, clinical regression of the scleral nodule was observed in right eye, maintaining reduced scleral thickness. High frequency ultrasound assisted in the diagnosis of nodular scleritis during the phases of treatment and in the identify its characteristic sequel feature, the scleral thinning.
\end{abstract}

Keywords: Scleritis/diagnosis; Scleritis/ultrasonography; Ultrasonography/methods; Biomicroscopy/methods; Case report

\section{INTRODUÇÃO}

A esclerite é uma doença grave e progressiva que acomete o tecido episcleral superficial, profundo e a esclera ${ }^{(1)}$. Uma vez que as estruturas colagenosas da esclera e da episclera são comparados à estrutura sinovial, as doenças que acometem as estruturas articulares geralmente atingem a bainha escleral-episcleral (2).

A esclera é uma camada de baixa distensibilidade, com espessura que varia de 0,3 a 1,0 milímetros e é composta por feixes densos de colágeno, fibras elásticas, fibroblastos, proteoglicanos e glicoproteínas ${ }^{(3)}$. Em condições normais, ao exame de ultrassonografia de alta frequência, a esclera apresenta-se como uma camada de alta refletividade em comparação à córnea, o que permite a delimitação da junção córneo-escleral, importante referência anatômica(4).

No processo inflamatório, há uma alteração do aspecto normal da esclera devido à desorganização e ao edema das fibras colágenas com acúmulo de células inflamatórias, que, em algumas fases, mostra características compatíveis com uma desordem mediada por células T, com implicação em relação ao tratamento da doença ${ }^{(5,6)}$.

A ultrassonografia ocular é um exame propedêutico útil para o diagnóstico dos diversos tipos de esclerite. Dependendo da porção ocular acometida, pode-se utilizar a ultrassonografia de $10 \mathrm{MHz}$, nos casos de esclerite posterior ${ }^{(7)}$ ou o ultrassom de alta frequência (UBM) para a avaliação da porção anterior da esclera.

\section{RELATO DE CASO}

Paciente do sexo feminino (RAP), branca, 27 anos de idade, apresentou quadro de uveíte intermediária bilateral associada ao edema macular identificado à biomicroscopia de fundo com a lente $78 \mathrm{D}$ e confirmado pelo exame de tomografia de coerência óptica (OCT) de $840 \mathrm{~nm}$ (Stratus, Zeiss), que mostrou espessamento foveal localizado e descolamento de retina na área foveal de ambos olhos; no olho direito (OD), espessura foveal de 323 micra com material exsudativo subfoveal (Figura 1A), no olho esquerdo, espessura foveal de 353 micra e material seroso subfoveal (Figura 1B). O exame de angiografia fluoresceínica demonstrou hiperfluorescência petaloide perifoveal (Figuras 2A e 2B) em ambos os olhos. Acuidade visual corrigida após tratamento clínico com corticoide tópico e oral era: OD: 20/300 e OE: 20/100; tonometria de aplanação (Goldmann) bilateral 12 mmHg.

Após 4 meses identificou-se uma elevação periférica da parede ocular temporal inferior à oftalmoscopia indireta no olho direito. Ao exame de ultrassonografia de alta frequência (UBM 840, Paradigm; transdutor de $50 \mathrm{MHz}$, técnica de imersão) identificou-se uma lesão abobadada local caracterizada por espessamento principalmente da coroide periférica, que apresentava um padrão de refletividade interna baixa e homogênea, de limites pouco definidos com os processos ciliares (Figura 3A). Na localização temporal inferior, a lesão nodular apresentava as seguintes dimensões: ântero-posterior (radial) e láte- 
ro-lateral (transversal) maiores que 5,0 mm (limite máximo de excursão do transdutor no equipamento) e espessura de $3,8 \mathrm{~mm}$ (Figura 3B). Observou-se também o acometimento escleral localizado 1,5 mm posteriormente ao limbo em posição temporal inferior através de redução do brilho (refletividade) da esclera na região central da lesão nodular, associado a afinamento escleral em área adjacente à região central, neste ponto sem alteração do padrão de hiper-refletividade típico da esclera (0,16 mm de espessura) (Figura 3B). Lesões císticas de paredes finas e regulares e de conteúdo anecoico foram identificadas na junção cilio-coroidal (Figura 3A)

O tratamento com triancinolona intravítrea foi realizado em ambos os olhos como tratamento para o edema macular acentuado. Após 3 meses da injeção intravítrea, houve melhora da acuidade visual em ambos olhos para 20/20. O exame de biomicroscopia ultrassônica do OD foi repetido após nove meses da injeção intravítrea de triancinolona e evidenciou regressão do nódulo escleral, restituição da espessura da coroide e dos padrões ecográficos da esclera, porém mantendo significativo afinamento escleral local (Figura 4).

Clinicamente, a paciente apresentava duas lesões avermelhadas e dolorosas na gengiva de aproximadamente $6 \mathrm{~mm}$ de diâmetro com aspecto granulomatoso, que foram submetidos a biópsia e evidenciaram um processo inflamatório crônico inespecífico à análise anatomopatológica. Associado ao quadro oftalmológico, a paciente apresentava sinusite, otite e diminuição dos padrões audiométricos, Os exames sorológicos apresentavam-se positivos para fator antinucleo 1/160 com pontilhado fino denso inespecífico e os anticorpos anticardiolipina mostravam lg de $22,3 \mathrm{U} / \mathrm{ml}$ e lgM de $24 \mathrm{U} / \mathrm{ml}$. Os demais exames: C- e P-ANCA, fator reumatoide, CH50, C3, C4, anti-DNA, anti-Ro, anti-La, anti-Sm, anti-RNP, anticoagulante lúpico, assim como hemograma, transaminases, ureia, creatinina e urina mostravam resultados normais ou negativos. Não foi possível o estabelecimento do diagnóstico etiológico de uma doença autoimune, porém pela gravidade do quadro oftalmológico, a paciente iniciou tratamento com imunossupressores sistêmicos: azatioprina (100 mg/dia) e ciclosporina (200 mg/dia) e demonstrou melhora global do quadro.
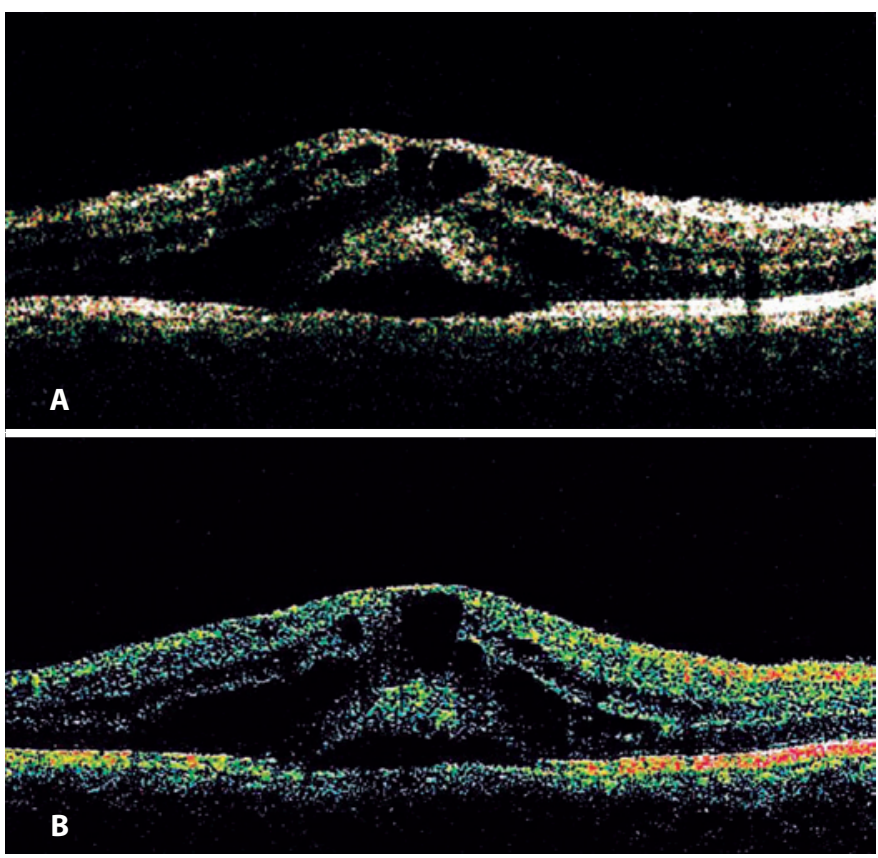

Figura 1. Tomografia de coerência óptica em caso de uveíte intermediária bilateral compatível com edema macular cistoide com espessamento foveal (OD: 323 micra; OE: 353 micra) associado a descolamento de retina na área foveal, com material exsudativo no $O D(A)$ e seroso no $O E(B)$.
Durante a evolução, à tentativa de se remover a imunossupressão, havia recidiva do quadro ocular.

Atualmente a paciente mantém uso de imunossupressores em doses reduzidas (azatioprina, $50 \mathrm{mg} / \mathrm{dia}$; e ciclosporina, $100 \mathrm{mg} / \mathrm{dia}$ ) e tem apresentado recidivas oculares com edema macular bilateral em intervalor de 7 a 12 meses, com necessidade de tratamento intraocular com injeções de triancinolona.
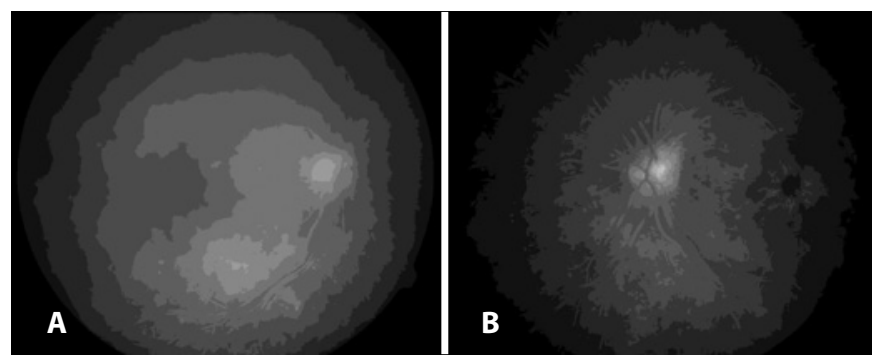

Figura 2. Em caso de uveíte intermediária, a angiografia fluoresceínica demonstra hiperfluorescência puntiforme por vazamento na retina da área macular e periférica, compatível com extravasamento de contraste capilar $(A=O D ; B=O E)$ e hiperfluorescência petaloide perifoveal em ambos os olhos, mais evidente no olho esquerdo (B), compatível com edema macular cistoide bilateral.
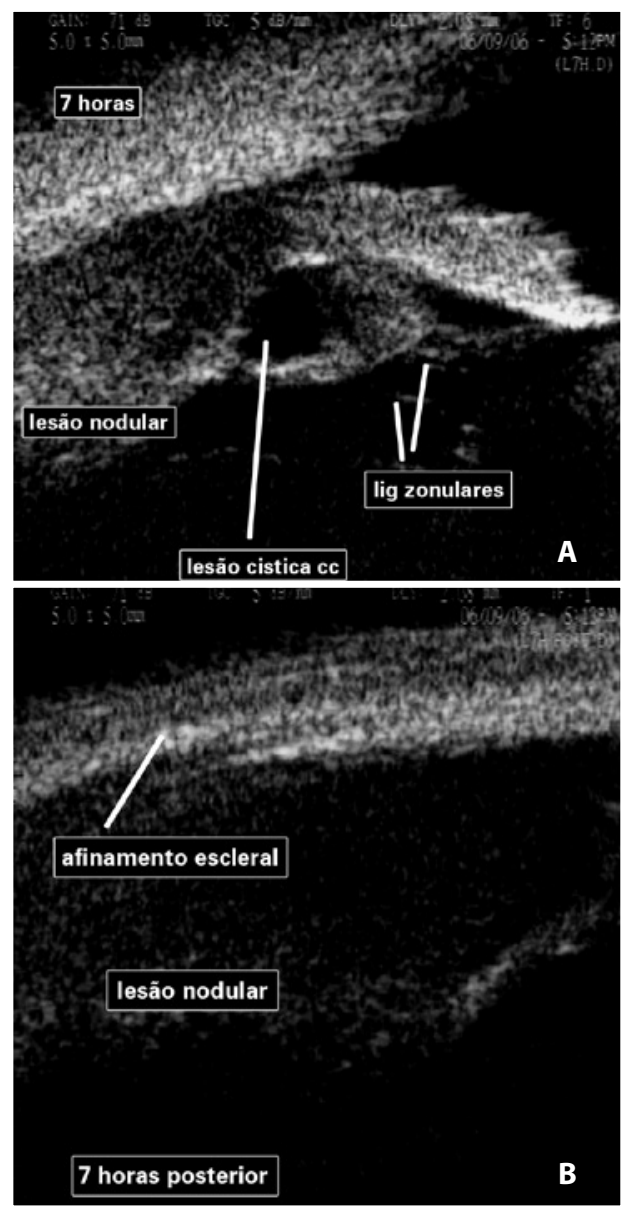

Figura 3. Ultrassonografia de alta frequência (UBM) em olho portador de esclerite nodular na região temporal inferior (meridiano de 7 horas). A) Porção anterior da lesão com espessamento coroidal (3,8 mm) associado a lesão cística de corpo ciliar. B) Porção posterior da lesão demonstra espessamento acentuado da coroide (espessura $=3,8 \mathrm{~mm}$ ) e espessura reduzida da esclera local. 


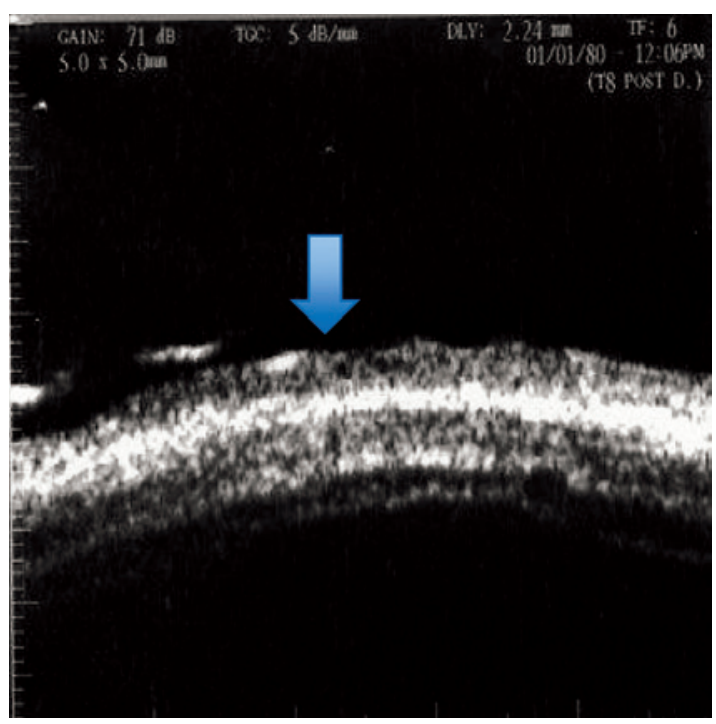

Figura 4. UBM realizado na região temporal inferior do olho direito que apresentou regressão do quadro de esclerite nodular após tratamento com triancinolona intravítrea. Observa-se espessura normal da coroide associada a reduzida espessura da esclera, sequela de afinamento escleral (seta), espessura local: 0,16 mm.

\section{DISCUSSÃO}

Os casos de esclerite nodular se apresentam à UBM como um espessamento focal da esclera, de margens distintas, com refletividade interna baixa e homogênea, e envolvimento ou não dos tecidos adjacentes como coroide e conjuntiva de diversas magnitudes ${ }^{(8,9)}$.

No caso descrito, o exame de UBM foi importante no diagnóstico da lesão e evidenciou uma área de afinamento da esclera associado a uma lesão nodular de grandes proporções que comprometia o tecido coroideo e escleral adjacentes. Posteriormente, após medicação sistêmica e intraocular, observou-se a regressão do nódulo coroideo com estabelecimento de afinamento localizado da esclera, quadro sequelar típico da esclerite, resultado da reorganização das fibras colágenas na esclera ${ }^{(10)}$

Gentile et al. ${ }^{(10)}$ relataram maior frequência de formações císticas de corpo ciliar situadas na face posterior da íris e no epitélio do corpo ciliar em pacientes com uveíte. Embora também tenham sido encontradas em pacientes sem inflamação, existe a hipótese de que tais formações císticas ocorram pela entrada de fluido entre os espaços interepiteliais na face posterior da íris e do corpo ciliar. No presente relato de caso foi observada uma lesão cística adjacente à lesão nodular.
Em casos de doença inflamatória ocular, tanto na fase aguda como crônica, o edema macular é uma importante causa de prejuízo visual|(11). A injeção intravítrea de anti-inflamatório tem se mostrado uma forma eficaz de administração do medicamento no tratamento de edema cistoide em uveítes ${ }^{(12)}$. No presente caso, a injeção intravítrea de triancinolona utilizada para promover a regressão do edema macular, permitiu também a melhora do quadro de esclerite nodular, sem recidiva da mesma durante um período de 15 meses.

Em casos de esclerite nodular, o envolvimento com uma doença sistêmica é evidenciado com frequência, porém como o diagnóstico pode ser tardio em relação à apresentação do quadro agudo, e, portanto, requer-se um acompanhamento clínico.

\section{CONCLUSÃO}

A ultrassonografia de alta frequência auxiliou ao diagnóstico da esclerite nodular durante as fases de tratamento e na identificação da sua sequela característica, o afinamento escleral.

\section{REFERÊNCIAS}

1. Urbano AP, Urbano AP, Urbano I, Kara-José N. Episclerite e esclerite. Arq Bras Oftalmol. 2002;65(5):591-8.

2. Akpek EK, Uy HS, Christen W, Gurdal C, Foster CS. Severity of episcleritis and systemic disease association. Ophthalmology. 1999;106(4):729-31.

3. Foster CS, Sains de la Maza M. Clinical considerations of episcleritis and scleritis: the Massachusetts Eye and Ear Infirmary experience. Foster CF, Sains de la Maza M. The Sclera. New York: Springer; 1994; p.95-136.

4. Pavlin CJ, Easterbrook M, Hurwitz JJ, Harasiewicz K, Eng P, Foster FS. Ultrasound biomicroscopy in the assessment of anterior scleral disease. Am J Ophthalmol. 1993; 116(5):628-35

5. Bernauer W, Daicker B. [Inflammatory cellular infiltration in scleritis]. Ophthalmologe. 1995;92(1):46-8. German.

6. Bernauer W, Watson PG, Daicker B, Lightman S. Cells perpetuating inflammatory response in scleritis. Br J Ophthalmol. 1994;78(5):381-5.

7. Machado DO, Curi AL, Bessa TF, Campos WR, Oréfice F. Esclerite posterior: características clínicas, associação sistêmica, tratamento e evolução de 23 pacientes. Arq Bras Oftalmol. 2009;72(3):321-6.

8. Sternlicht T, Allemann N, Muccioli C. O emprego da biomicroscopia ultrassônica no diagnóstico e evolução clínica dos diferentes tipos de esclerite anterior. Arq Bras Oftalmol. 2001;64(3):229-32

9. Heiligenhaus A, Schilling M, Lung E, Steuhl KP. Ultrasound biomicroscopy in scleritis Ophthalmology. 1998;105(3):527-34.

10. Gentile RC, Liebmann JM, Tello C, Stegman Z, Weissman SS, Ritch R. Ciliary body enlargement and cyst formation in uveitis. Br J Ophthalmol. 1996;80(10):895-9.

11. Rothova A, Suttorp-van Schulten MS, Frits Treffers W, Kijlstra A. Causes and frequency of blindness in patients with intraocular inflammatory disease. Br J Ophthalmol. 1996; 80(4):332-6.

12. Young S, Larkin G, Branley M, Lightman S. Safety and efficacy of intravitreal triamcinolone for cystoid macular oedema in uveitis. Clin Exp Ophthalmol. 2001;29(1):2-6. Comment in Clin Experiment Ophthalmol. 2001;29(1):1. 